\title{
Melding Industrial-Organizational Scholarship and Practice for Environmental Sustainability
}

\author{
SUSAN E. JACKSON \\ Rutgers University and Lorange Institute of Business, Zurich
}

Ones and Dilchert (2012) argue persuasively for industrial-organizational $(\mathrm{I}-\mathrm{O})$ psychologists to get more involved in creating positive environmental change. What accounts for the low involvement of I-O psychologists? Given the complexity of environmental issues, how do we get started? This commentary provides suggestions for melding I-O psychology practice and research to generate knowledge about how HRM practices can be used to create environmentally sustainable organizations.

\section{Adopt a Systems Perspective}

A systems perspective is fundamental to environmental science and understanding the environmental performance of organizations. Effective $\mathrm{I}-\mathrm{O}$ practitioners garner the support of other powerful players by understanding the larger context-including the organization's business strategy, its culture and history, as well as the broader institutional and social environment that impinges on them (see Ambec \& Lanoie, 2012; Staffelbach, Brugger, \& Bäbler, 2012). In contrast to merely following so-called "best practices," adopting a systems perspective requires creating and adapting HRM interventions to fit the specific situation.

The means through which HRM practices can support environmental goals may depend on whether the business

Correspondence concerning this article should be addressed to Susan E. Jackson.

E-mail: sjackson@smlr.rutgers.edu

Address: HRM Department, School of Management and Labor Relations, 94 Rockafeller Road, Piscataway, NY 07830 imperatives associated with environmental sustainability emphasize improving efficiency and lowering costs, or advancing technological innovation to create new products, or attracting more customers and improving market share. Likewise, useful research pays attention to the organizational contexts in which people are embedded, as Ones and Dilchert point out. For example, research on environmental knowledge and attitudes around the world reveals significant country-level differences in what people mean when they refer to "the environment" and what they think they know about environmental issues. When asked about the nature of their environmental concerns, the Swiss are more likely to mention climate change whereas Italians are more likely to mention pollution in their cities and towns. Citizens of northern European countries report having greater knowledge about environmental issues compared to those living further south (Eurobarometer, 2008). Environmental attitudes and knowledge may also vary across industries and stages of economic development in the country. Such contextual conditions likely influence the design of effective recruitment, selection, socialization, training, leadership development practices, and so forth. Comparative research that sheds light on how environmental attitudes and knowledge are distributed across countries, industries, and stages of economic development would be especially valuable for multinational corporations that wish to achieve consistency in employee behaviors and outcomes throughout their dispersed facilities. 
The complexity of modern organizations means that achieving alignment between environmental goals and management practices is an evolutionary process. Besides the contextual factors already mentioned, the effectiveness of specific interventions may depend on the evolutionary stage of the organization's trajectory toward environmental sustainability. Our knowledge of such trajectories is quite limited; no one knows which evolutionary path is most common or most efficient. To improve our understanding of how HRM practices can be used to promote environmental sustainability, research and analysis are needed to address questions such as:

- Is alignment between HRM practices and environmental strategy best achieved by focusing first on performance evaluation and rewards, or, is it better to begin by preparing the workforce through extensive socialization and training? Is it more effective to first change behavior, or first change attitudes and hope that behavioral changes will follow?

- Under what circumstances and for which outcomes is it more effective to rely on voluntary efforts to create employee engagement at the lower levels of the organization, and when or is it more effective to impose changes from above? That is, when are grass roots initiatives more effective than top-down mandates for improving environmental performance? Does the answer depend on employees' current environmental attitudes and/or knowledge?

- Where in the organization (which functions, at what levels) are managers most likely to readily understand the value of aligning HRM practices with environmental goals, and become willing partners in change efforts? What are the experiences and characteristics of managers who are most likely to be productive allies in efforts to align HRM practices with environmental sustainability goals?

\section{Collaborate With External Stakeholders}

Typically, I-O psychologists recognize the value of attending to differences among subgroups of employees; they are prepared to deal with differences associated with gender, education, age, and so forth. Achieving environmental sustainability also requires understanding the perspectives of external stakeholders, such as customers, suppliers, business alliance partners, and investors.

When environmental sustainability is the objective, alliance partners upstream in the value chain (suppliers of raw materials and parts, product assemblers and manufacturers) and downstream (distributors, consumers) are important stakeholders. Efforts to reduce a company's environmental footprint can succeed only if environmentally friendly practices permeate the entire life cycle of products and services. In addition, these various stakeholders may collaborate in their efforts to influence government and industry regulations, participate in consortia to develop new industry standards and metrics for assessing environmental performance, share responsibility for workforce training, influence the energy resources and transportation options of the community, and so on. Thus, HRM practices might appropriately target and/or be designed through collaboration with these various strategic partners. Likewise, research that engages a broad array of stakeholders is more likely to produce knowledge that is useful for promoting system-wide environmental sustainability.

Daimler AG's approach to environmental sustainability reflects an awareness of the value of stakeholder inclusiveness (see Deller, Schnieders, \& Titzrath, 2012). Each year, the company hosts an annual Sustainability Dialogue event for various stakeholder groups to solicit their input in setting environmental goals and seek their cooperation in finding solutions that will help achieve the goals. To promote mutually beneficial relationships with an organization's various stakeholders and make greater strides toward environmental sustainability, 
I-O psychologists might consider questions such as:

- How do various stakeholders evaluate whether the HRM system supports stated environmental goals and aspirations? What information do they pay attention to, and does the source of the information matter?

- What messages do HRM practices (recruiting practices, sources of new hires, qualifications required for promotion into senior positions) communicate to various stakeholders? How can HRM practices be used to improve the consistency and effectiveness of the organization's environmental messaging across all stakeholders?

- How can organizations create alignment between elements of the HRM system and other business activities that are visible to external stakeholders, such as marketing campaigns, accounting practices, and facilities location and management? What are the consequences of misalignment for internal and external stakeholders?

\section{Leverage and Promote Organizational Learning}

As organizations journey toward environmental sustainability, their progress reflects their change management capabilities. Past experiences in creating organizational change-whether successful or unsuccessful_can prepare an organization for future change efforts. Thus it is likely that lessons learned from prior efforts to implement total quality management or customer service initiatives prepared some firms for greater success with subsequent initiatives aimed at improving environmental performance. Surely the recent success of McDonald's UK's environmental sustainability efforts (see Haddock-Millar, MüllerCamen, \& Miles, 2012) is due partly to that company's long history of implementing organizational change in response to changing external conditions. I-O psychologists are well-schooled in the design and evaluation of individual learning, but we need to improve our understanding of and capacity for organizational learning. Questions needing answers include:

- How can we assess whether leaders, HR professionals, and the organization as a whole have the capabilities required to effect change?

- Does experience with earlier strategic change initiatives predict success in improving environmental performance? How can HRM practices be used to ensure that lessons learned during change initiatives are retained, shared and leveraged throughout the organization?

- How does the amount and pattern of employee turnover influence an organization's ability to learn from past successes and failures?

\section{Engage Employees}

By deploying effective HRM practices, some organizations are already improving their performance against strategic goals such as energy efficiency, waste reduction, zero emissions, and other environmental indicators. But is tinkering with elements of the HRM system sufficient to ignite the full potential of an organization's workforce? Effective environmental initiatives surely will include some traditional HRM practices, but novel experiential approaches to creating change have great appeal and may be more effective in creating a truly engaged workforce. Formal programs and schemes designed to push employees toward environmentally responsible behavior on the job may be less effective than supporting employees' voluntary and informal participation in environmental activities that are only weakly associated with their work (e.g., gardening, travel, science education). Given our human desire for selfdetermination, perhaps the most significant question for I-O psychologists to answer is this:

- How can the free will and idiosyncratic interests of employees be 
addressed and leveraged by employers as they strive to engage the hearts and minds of employees for the purpose of achieving environmental sustainability?

\section{Conclusion}

Interdependencies between the health of our planet and the health and prosperity of our human population have slowly become more evident. Pleas that urge us to pay attention to this fragile relationship are growing louder. Regardless of the reasons for an organization's environmental initiatives, I-O psychologists are being called upon to design, implement, and evaluate workforce interventions to support those environmental initiatives. If we embrace this challenge, surely we can increase the environmental sustainability of our workplaces.

\section{References}

Ambec, S., \& Lanoie, P. (2012). The strategic importance of environmental sustainability. In
S. E. Jackson, D. S. Ones, \& S. Dilchert (Eds.), Managing human resources for environmental sustainability (pp. 21-35). San Francisco, CA: Jossey-Bass/Wiley.

Deller, J., Schnieders, T., \& Titzrath, T. (2012). HR and sustainability at Daimler AG. In S. E. Jackson, D. S. Ones, \& S. Dilchert (Eds.), Managing human resources for environmental sustainability (pp. 298-308). San Francisco, CA: Jossey-Bass/Wiley.

Eurobarometer (2008). Attitudes of European citizens towards the environment. European Commission Report.

Haddock-Millar, J., Müller-Camen, M., \& Miles, D. (2012). Human resource development initiatives for managing environmental concerns at McDonald's UK. In S. E. Jackson, D. S. Ones, \& S. Dilchert (Eds.), Managing human resources for environmental sustainability (pp. 341 -361). San Francisco, CA: Jossey-Bass/Wiley.

Ones, D. S., \& Dilchert, S. (2012). Environmental sustainability at work: A call to action. Industrial and Organizational Psychology: Perspectives on Science and Practice, 5, 444-466.

Staffelbach, B., Brugger, E. A., \& Bäbler, S. (2012). The role of strategic context in environmental sustainability initiatives: Three case studies. In S. E. Jackson, D. S. Ones, \& S. Dilchert (Eds.), Managing human resources for environmental sustainability (pp. 36-60). San Francisco, CA: Jossey-Bass/Wiley. 